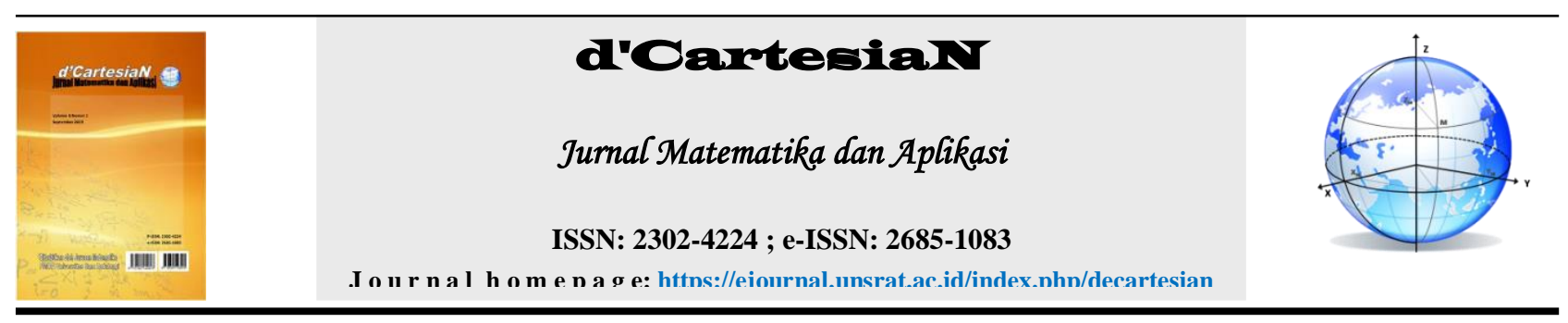

\title{
Pengaruh Pelayanan Di Fakultas Matematika Dan Ilmu Pengetahuan Alam Terhadap Kepuasan Mahasiswa Fmipa Unsrat Menggunakan Analisis Regresi Logistik Ordinal
}

\author{
Fadhila Minabari ${ }^{1}$, Jullia Titaley ${ }^{1}$, Nelson Nainggolan ${ }^{1 *}$ \\ ${ }^{1}$ Jurusan Matematika-Fakultas Matematika dan Ilmu Pengetahuan Alam-Universitas Sam Ratulangi Manado,Indonesia
}

${ }^{*}$ Corressponding author :n-nelson@unsrat.ac.id

\begin{abstract}
A B S T R A K
Tujuan dari penelitian ini adalah untuk mengetahui bagaimana model regresi logistik ordinal terhadap pengaruh pelayanan di fakultas MIPA terhadap kepuasan mahasiswa, mengetahui aspekaspek pelayanan apa saja yang mempengaruhi tingkat kepuasan mahasiswa dan mengetahui seberapa besar variabel independen dapat mempengaruhi variabel dependen. Hasil penelitian menunjukan bahwa regresi ordinal dan persamaannya layak digunakan, variabel yang berpengaruh secara signifikan terhadap kepuasan mahasiswa di Fakultas MIPA adalah aspek administrasi, aspek pengajaran dan aspek sarana prasarana. Model regresi logistik ordinal aspek administrasi, aspek pengajaran dan aspek sarana prasarana mempengaruhi penilaian kepuasan mahasiswa secara keseluruhan sebesar 50,3\%.
\end{abstract}

\section{INFO ARTIKEL}

Diterima : 15 juli 2019

Diterima setelah revisi : 23 Juli 2019

Tersedia online : 25 Juli 2019

\section{Kata Kunci:}

Kepuasan mahasiswa

Regresi logistik ordinal

\section{A B S T RA C T}

The purpose of this study was to find out how the ordinal logistic regression model of the influence of services at the MIPA faculty on student satisfaction, knowing what aspects of services affect the level of student satisfaction and knowing how much the independent variable can affect the dependent variable. The results showed that ordinal regression and its equations were feasible to use, variables that significantly influence student satisfaction at the MIPA Faculty were administrative aspects, teaching aspects and aspects of infrastructure. Ordinal logistic regression models for administrative aspects, teaching aspects and infrastructure facilities affect the overall assessment of student satisfaction by $50,3 \%$.

\section{ARTICLE INFO}

Accepted : 15 July 2019

Accepted after revision : 23 July 2019

Available online : 25 July 2019

\section{Keywords:}

student satisfaction

ordinal logistic regression

\section{PENDAHULUAN}

Pendidikan adalah proses transfer ilmu, pola pikir, akhlak dan moral sumber daya manusia. Perkembangan pendidikan sangat berpengaruh terhadap perkembangan suatu negara dalam segala aspek, baik Ekonomi, Sosial, Politik, Budaya, Pertahanan Keamanan, Teknologi, dan aspek yang lainnya. Inilah peranan penting dunia pendidikan untuk berkembangnya suatu negara. Dan salah satu tempat untuk menuntut ilmu yaitu Perguruan Tinggi.

Menurut UU No. 20 tahun 2003 pasal 19 ayat 1: "yang dimaksud perguruan tinggi adalah pendidikan setelah pendidikan menengah mencakup program pendidikan diploma, sarjana, magister, spesialis, dan doktor yang diselenggarakan oleh perguruan tinggi”. Selain itu perguruan tinggi juga mempunyai pengertian pendidikan pada jenjang yang lebih tinggi dari pada pendidikan menengah di jalur pendidikan sekolah. Perguruan tinggi di sini adalah tingkatan universitas yang terdiri atas sejumlah fakultas yang menyelenggarakan pendidikan akademik dan/atau profesional dalam sejumlah disiplin ilmu tertentu.

Ada pula tugas dan fungsi dari perguruan tinggi itu sendiri, secara khusus tugas perguruan tinggi dapat kita lihat dalam PP No.30 tahun 1990 tentang Perguruan Tinggi dalam ketentuan umum, Pasal 1 ayat 2: "Perguruan tinggi adalah satuan pendidikan yang menyelenggarakan pendidikan tinggi". Sedangkan fungsi dari perguruan tinggi, menurut [1] pendidikan tinggi antara lain berfungsi untuk mempersiapkan peserta didik menjadi manusia yang memiliki perilaku, nilai dan norma sesuai sistem yang berlaku sehingga mewujudkan totalitas manusia yang utuh dan mandiri sesuai tata cara hidup bangsa. Kualitas suatu perguruan tinggi sangat ditentukan oleh mutu pelayanan yang diberikan, dimana pelayanan yang bermutu dapat diindetifikasi melalui kepuasan pelanggan dalam hal ini adalah mahasiswa. Bagi sebuah perguruan tinggi kepuasan layanan lebih diorientasikan kepada mahasiswa karena mahasiswa merupakan pelanggan primer dari perguruan tinggi. Perguruan tinggi sebagai industri jasa harus terus 
memikirkan pentingnya pelayanan pelanggan secara lebih matang, kerena kini semakin disadari bahwa pelayaan dan kepuasaan pelanggan merupakan aspek vital dalam rangka bertahan dalam bisnis dan memenagkan persaingan [2]. Layanan yang berkualitas akan memberikan kepuasan kepada mahasiswa. Kepuasan mahasiswa ditujukan dengan adanya keloyalan mahasiswa pada perguruan tinggi dan mahasiswa akan menceritakan mengenai layanan akademik yang memuaskan kepada orang lain. Kepuasan mahasiswa merupakan misi yang harus diwujudkan apabila suatu lembaga pendidikan ingin diterima oleh masyarakat serta dapat terus eksis dan berkembang di tengah-tengah dukungan masyarakat. Bentuk pelayanan yang diterima oleh mahasiswa di perguruan tinggi dapat mencakup pelayanan kegiatan akademik, kemahasiswaan dan administrasi. Fakultas Matematika dan Ilmu Pengetahuan Alam Universitas Sam Ratulangi (FMIPA UNSRAT) merupakan lembaga pendidikan yang dapat dikatakan sebuah layanan jasa bidang pendidikan. Dalam pemberian jasa pendidikan FMIPA dituntut tidak hanya memberikan jasa dalam bentuk fisik tetapi juga memberikan pelayanan yang lebih profesional sehingga tercapai kualitas pelayanan yang baik yaitu kualitas pelayanan pendidikan yang didukung oleh tenaga pengajar yang kompeten dalam bidangnya [3].

\section{Kualitas Pelayanan}

Pengertian kualitas pelayanan adalah sebuah kata yang bagi penyedia jasa merupakan sesuatu yang harus dikerjakan dengan baik [4]. Sedangkan definisi pelayanan menurut Gronroos adalah suatu aktivitas atau serangkaian aktivitas yang bersifat tidak kasat mata yang terjadi sebagai akibat adanya interaksi antara konsumen dengan karyawan atau hal-hal lain yang disediakan oleh perusahaan pemberi pelayanan yang dimaksud untuk memecahkan permasalahan konsumen / pelanggan[5]. Pelayanan merupakan faktor yang amat penting khususnya bagi perusahaan yang bergerak dibidang jasa.Dimana hal ini fisik produk biasanya ditunjang dengan berbagai macam inisial produk.

Adapun inti produk yang dimaksud biasanya merupakan jasa tertentu.Oleh karena itu pentingnya mengetahui secara teoritis tentang batasan, pengertian dan faktor-faktor yang mempengaruhi dari pada pelayanan itu sendiri. Pelayanan pelanggan ini sangat penting artinya bagi kehidupan suatu perusahaan, karena tanpa pelanggan, maka tidak akan terjadi transaksi jual beli diantara keduanya. Untuk itu kegiatan pelayananperusahaan haruslah berorientasi pada kepuasan pelanggan.

Kepuasan pelanggan dalam praktek tidak cukup hanya dengan terpenuhinya kepuasan pribadi untuk melayani konsumen yang bersangkutan tetapi juga harus diperhatikan hal-hal sebagai berikut :

1. Pelanggan adalah orang paling penting

2. Pelanggan adalah objek yang dapat memberikan

keuntungan bagi perusahaan

3. Pelanggan bukanlah lawan bicara yang perlu diajak berdebat, bila terpaksa, maka pihak yang menang haruslah pihak pelanggan

4. Pelanggan adalah raja, sekali ia kalah dalam berargumentasi maka ia akan pindah ke produk lain

5. Pelanggan adalah manusia biasa yang memiliki perasaan senang, benci, bosan, dan adakalanya mempunyai prasangka yang tidak beralasan

6. Pelanggan dalam usaha mendapatkan pelayanan selalu ingin didahulukan, diperhatikan, dan ingin diistimewakan serta tidak ingin diremehkan begitu saja

\section{Tujuan dan Fungsi Pelayanan}

Kualitas pelayanan yang diberikan oleh setiap perusahaan tentunya mempunyai tujuan. Umumnya tujuan dengan diadakannya pelayanan adalah agar konsumen merasakan adanya kepuasan dan dampaknya bagi perusahaan akan memperoleh laba maksimum. Kualitas pelayanan diberikan kepada konsumen harus berfungsi untuk lebih memberikan kepuasan yang maksimal, oleh karena itu dalam rangka memberikan pelayanan harus dilakukan sesuai dengan fungsi pelayanan.

\section{Analisis Regresi}

Analisis Regresi ialah suatu teknik analisis yang dapat menjelaskan hubungan antara dua atau lebih hubungan antara variabel-variabel yang mengandung sebab akibat[6]. Analisis regresi merupakan metode yang dapat digunakan menganalisis hubungan bermodal antar variabel. Hubungan bermodel tersebut yang dapat diekspresikan dalam bentuk persamaan yang menghubungakn antara dependent variabel $\mathrm{Y}$ dengan satu independent variabel X. Jika dalam model regresi terdapat satu variabel bebas yang dinamakan $\mathrm{X}$ dan satu variabel tak bebas yang bergantung pada $\mathrm{X}$ dinamakan $\mathrm{Y}$, maka hubungan diantara variabel ini dimaksudkan melalui model matematik disebut model regresi. Jika hanya terdapat satu variabel respon $\mathrm{Y}$ dan satu variabel bebas X, maka model yang diperoleh dapat disebut model regresi sederhana dan apabila variabel bebasnya lebih dari satu maka model yang diperoleh dapat disebut model regresi ganda. Variabel prediktor dalam analisis regresi ini seringkali bersifat kuantitatif [6].

\section{Regresi Logistik}

Registik Logistik merupakan analisis yang digunakan untuk melihat hubungan antara variabel respon yang bersifat kategorik (kualitatif) dan variabelvariabel prediktor yang bersifat nominal atau ordinal (kualitatif) maupun interval atau rasio (kuantitatif) [7].

Regresi logistik biner merupakan suatu metode analisis data yang digunakan untuk mencari hubungan anatara variabel respon $(\mathrm{Y})$ yang biner atau dikotomus dengan variabel prediktor (X) yang bersifat politokomus. Hasil dari variabel respon (Y) terdiri dari 2(dua) kategori yang biasanya dinotasikan dengan $\mathrm{Y}=1$ (sukses) dan $\mathrm{Y}=$ o (gagal). Bentuk umum regresi logistik adalah sebagai berikut [8]: 
$\pi(X)=\frac{\exp \left(\beta_{0}+\beta_{1} X_{1}+\cdots+\beta_{k} X_{k}\right)}{1+\exp \left(\beta_{0}+\beta_{1} X_{1}+\cdots+\beta_{k} X_{k}\right)}$

Kemudian dilakukan transformasi logit untuk menyederhanakan persamaan di atas dalam bentuk logit sebagai berikut.

$$
g(x)=\ln \left[\frac{\pi(X)}{1-\pi(X)}\right]=\beta_{0}+\beta_{1} X_{1}+\beta_{2} X_{2}+\cdots+\beta_{k} X_{k}
$$

\section{Regresi Logistik Ordinal}

Regresi logistik ordinal merupakan salah satu analisis regresi yang digunakan untuk menganalisa hubungan antara variabel $(\mathrm{Y})$ dengan variabel prediktor $(\mathrm{X})$, dimana variabel respon $(\mathrm{Y})$ bersifat politokomus dengan skala ordinal [9].

Regresi logistik adalah model regresi yang digunakan apabila variabel respon bersifat kualitatif.Model ini terdiri dari regresi logistik sederhana yang bersifat dikotomus yang mensyaratkan variabel respon terdiri dari dua kategori, dan regresi logistik politokomus dengan variabel respon lebih dari dua kategori.Regresi logistik politokomus dengan variabel respon yang bersifat sering dikenal dengan regresi logistik ordinal.Jumlah kategori pada variabel respon adalah sebanyak kategori. Contoh variabel respon pada metode regresi logistik ordinal dengan jumlah kategori tiga adalah rendah, sedang dan tinggi (ada tingkatan dalam kategori variabel respon) [8].

\section{Model Logit Kumulatif}

Model yang dapat dipakai untuk regresi logistik ordinal adalah model logit. Model logit tersebut adalah model logit kumulatif, pada model ini terdapat sifat ordinal dari respon $\mathrm{Y}$ yang dituangkan dalam peluang kumulatif sehingga model logit kumulatif merupakan model yang didapatkan dengan cara membandingkan peluang kumulatif yaitu peluang kurang dari atau sama dengan ketegori respon ke-j pada $\mathrm{p}$ variabel prediktor yang dinyatakan dalam vektor $\mathrm{X}, \mathrm{P}(\mathrm{Y} \leq \mathrm{j} \mid \mathrm{X})$ dengan peluang lebih besar daripada kategori respon ke-j, $\mathrm{P}(\mathrm{Y}>\mathrm{j} \mid \mathrm{X})$ [8]. Peluang kumulatif, $\mathrm{P}(\mathrm{Y} \leq \mathrm{j} \mid \mathrm{X})$ didefinisikan sebagai berikut:

$$
P(Y \leq j \mid X)=\frac{\exp \left(\beta_{0 j}+\sum_{k=1}^{p} \beta_{k} x_{k}\right.}{1+\exp \left(\beta_{0 j}+\sum_{k=1}^{p} \beta_{k} x_{k}\right.}
$$

Keterangan $j=1,2, \ldots, j$ adalah kategori respon [10].

\section{Metode Kemungkinan Maksimum}

Tujuan digunakannya metode kemungkinan maksimum adalah untuk menjelaskan peluang pengamatan sebagai suatu fungsi dari parameter yang tidak diketahui dapat dibangun dengan suatu fungsi yang disebut likelihood function. Metode digunakan untuk memaksimumkan nilai dari fungsi tersebut digunakan metode kemungkinan maksimum [8]. Cara untuk menaksir parameter pada regresi logistik ordinal adalah dengan metode kemungkinan maksimum. Kategori respon pada regresi logistik ordinal mempunyai urutan atau ordering maka model logit yang digunakan adalah model logit kumulatif. Model logit multiple respon dalam model logit adalah:

$$
\text { logit } P \leq j \mid X=\emptyset_{j}+\beta^{T} X, j=1,2, \ldots, j-1
$$

Keterangan bahwa $\theta$ adalah vektor parameter intersep dan $\beta^{T}=\left(\beta_{1}, \beta_{2}, \ldots, \beta_{p}\right)$ adalah vektor parameter kemiringan atau slope. Jika $\theta_{j}<\theta_{j+1}$ maka model ini adalah model kumulatif dengan kemiringan yang sama yaitu model garis regresi yang berdasarkan pada peluang kumulatif kategori respon.

Jika

$Y_{j}(X)=\pi_{1}(X)+\pi_{2}(X)+\cdots+\pi_{j}(X)$

Maka

$Y_{1}(X)=\pi_{1}(X)$

$Y_{2}(X)=\pi_{1}(X)+\pi_{2}(X)$

$Y_{j}(X)=\pi_{1}(X)+\pi_{2}(X)+\cdots+\pi_{j}(X)$

Jika terdapat $\mathrm{J}$ kategori respon maka model logistik ordinal yang terbentuk adalah[8]:

$$
\begin{aligned}
\operatorname{logit}\left(Y_{2}\right) & =\ln \left(\frac{Y_{2}}{1-Y_{2}}\right) \\
= & \theta_{2}+\beta_{1} X_{1}+\beta_{2} X_{2}+\cdots+\beta_{p} X_{p} \\
\operatorname{logit}\left(Y_{j-1}\right) & =\ln \left(\frac{Y_{j-1}}{1-Y_{j-1}}\right) \\
= & \theta_{j-1}+\beta_{1} X_{1}+\beta_{2} X_{2}+\cdots+\beta_{p} X_{p}
\end{aligned}
$$

\section{Interpretasi Parameter dalam Model Regresi Logistik}

Jika persamaan Regresi di tulis kembali sebagai $\mathrm{g}(\mathrm{x})$ merupakan fungsi hubungan dari model regresi logistik yang disebut fungsi hubungan logit.

$$
\begin{aligned}
g(x)=\operatorname{logit}(\pi(x)) & =\ln \left(\frac{\pi(x)}{1-\pi(x)}\right) \\
= & \beta_{0}+\beta_{1} X_{1}+\beta_{2} X_{2}+\cdots+\beta_{k} X_{k}
\end{aligned}
$$

Variabel prediktor yang diamati merupakan variabel kategorik dengan lebih dari dua kategori (polytomous) maka interpretasi parameter untuk variabel ini menggunakan bantuan variabel dummy. Jika terdapat $\mathrm{J}$ kategori, akan digunakan $(\mathrm{J}-1)$ variabel dummy dengan satu buah kategori akan dijadikan sebagai kategori referensi. Interpretasi dilakukan dengan cara yang sama dengan interpretasi pada variabel prediktor dikotomi yaitu tiap-tiap kategori dibandingkan dengan kategori rujukannya [8].

\section{Uji tiap-tiap parameter model (uji W)}

Langkah-langkah pengujian keberartian parameter regresi dengan menggunakan uji Wald adalah:

1. Rumusan Hipotesis

$H_{0}: \beta_{k i}=$ (parameter dalam model,untuk variabel prediktor ke-k dengan kategori ke-i tidak berarti)

$H_{1}: \beta_{k i} \neq 0=$ (parameter dalam model,untuk variabel prediktor ke-k dengan kategori ke-i tidak berarti)

2. Besarnya yang diperlukan Hitung $\hat{\beta}_{k i}$ dan $S E\left(\hat{\beta}_{k i}\right)$

3. Statistik Uji

$$
z^{2}=\left(\frac{\widehat{\beta}_{k i}}{\operatorname{SE}\left(\widehat{\beta}_{k i}\right)}\right)^{2}
$$

4. Kriteria pengujian

Mengambil taraf nyata $\alpha$ maka $H_{0}$ ditolak jika $z^{2}>$ $X_{(\alpha, 1)}^{2}$ 
5. Kesimpulan penaksiran $H_{0}$ ditolak atau diterima [11].

\section{METODOLOGI PENELITIAN \\ Waktu dan Tempat Penelitian}

Penelitian dilaksanakan pada bulan Desember 2018 - April 2019. Tempat pelaksanaan bertempat di fakultas matematika dan ilmu pengetahuan alam universitas sam ratulangi manado.

\section{Populasi dan Sampel}

\section{a. Populasi}

Populasi dalam penelitian ini adalah mahasiswa aktif tahun ajaran 2018/2019 semester genap Fakultas MIPA sebanyak 1,328 mahasiswa.

\section{b. Sampel}

Sampel terpilih dalam penelitian ini berjumlah 307 diperoleh dengan menggunakan rumus slovin:

$$
n=\frac{N}{N d^{2}+1}
$$

Dimana:

$n=$ Jumlah sampel

$N=$ Jumlah Populasi

$d=$ Presisi yang ditetapkan $(5 \%)$

Jumlah Mahasiswa yang diambil adalah sebanyak 307, maka:

$$
n=\frac{1.328}{1.328(0,05)^{2}+1}=307
$$

Namun yg diambil hanya 303 responden.Teknik sampling yg digunakan adalah teknik sampling stratifikasi.Dengan stratifikasi terhadap jumlah mahasiswa program studi.Dengan menggunakan rumus proporsi terhadap jumlah mahasiswa program studi.

\section{Variabel dan Data Penelitian}

Variabel merupakan besaran yang memiliki variasi nilai, dalam kegiatan ini meliputi variabel bebas (Independen) dan variabel terikat (Dependen). Variabel bebas dalam penelitian ini ada 3 variabel terdiri dari 23 indikator Variabel dan 1 variabel terikat untuk pelayanan secara keseluruhan di Fakultas MIPA.

\begin{tabular}{|c|c|c|c|c|}
\hline $\begin{array}{l}\mathrm{N} \\
\mathrm{o}\end{array}$ & $\begin{array}{c}\text { Aspek } \\
\text { Administrasi } \\
\text { (X1) }\end{array}$ & $\begin{array}{c}\text { Aspek } \\
\text { Pengajaran } \\
\text { (X2) }\end{array}$ & $\begin{array}{c}\text { Aspek } \\
\text { Sarana dan } \\
\text { Prasarana } \\
\text { (X3) }\end{array}$ & $\begin{array}{c}\text { Aspek } \\
\text { Kepuasan } \\
\text { Mahasiswa } \\
\text { (Y) }\end{array}$ \\
\hline 1 & $\begin{array}{l}\text { Kemudahan } \\
\text { Mengurus } \\
\text { Surat }\end{array}$ & $\begin{array}{l}\text { Perhatian } \\
\text { dosen terhadap } \\
\text { mahasiswa }\end{array}$ & $\begin{array}{l}\text { Ketersediaan } \\
\text { Area Parkir }\end{array}$ & \\
\hline 2 & $\begin{array}{l}\text { Keramahan } \\
\text { petugas } \\
\text { administrasi }\end{array}$ & $\begin{array}{l}\text { Ketepatanwakt } \\
\mathrm{u}\end{array}$ & $\begin{array}{l}\text { Kebersihan } \\
\text { toilet dan } \\
\text { lingkungan } \\
\text { kampus }\end{array}$ & \\
\hline 3 & $\begin{array}{l}\text { Kesediaan } \\
\text { petugas } \\
\text { perpustakaa } \\
\text { n }\end{array}$ & $\begin{array}{l}\text { Penyampaian } \\
\text { materi sesuai } \\
\text { dengan rencana }\end{array}$ & $\begin{array}{l}\text { Kelengkapan } \\
\text { ruang kelas }\end{array}$ & \\
\hline 4 & $\begin{array}{l}\text { Kemudahan } \\
\text { Sikadu }\end{array}$ & $\begin{array}{l}\text { Penyampaian } \\
\text { materi secara } \\
\text { jelas }\end{array}$ & $\begin{array}{l}\text { Fasilitas dan } \\
\text { kelengkapan } \\
\text { bukudi } \\
\text { perpustakaa } \\
\text { n }\end{array}$ & \\
\hline 5 & $\begin{array}{l}\text { Kemudahan } \\
\text { Sibima }\end{array}$ & & $\begin{array}{l}\text { Fasilitas lab } \\
\text { computer, } \\
\text { lab praktek }\end{array}$ & $\begin{array}{l}\text { Kepuasan } \\
\text { Mahasiswa } \\
\text { secara } \\
\text { keseluruha } \\
\text { n }\end{array}$ \\
\hline
\end{tabular}

Tabel 1.Variabel Penelitian

\begin{tabular}{clcl}
6 & $\begin{array}{l}\text { Jadwal } \\
\text { kuliah yang } \\
\text { tersusun } \\
\text { dengan baik }\end{array}$ & $\begin{array}{l}\text { Fasilitas } \\
\text { penunjang } \\
\text { kegiatan } \\
\text { mahasiswa }\end{array}$ \\
7 & $\begin{array}{l}\text { Kemudahan } \\
\text { memperoleh } \\
\text { informasi }\end{array}$ & $\begin{array}{c}\text { Bahan ajar } \\
\text { mudah } \\
\text { diperoleh }\end{array}$ & $\begin{array}{l}\text { Kecepatan } \\
\text { koneksi wifi }\end{array}$ \\
8 & & $\begin{array}{l}\text { Kenyamanan } \\
\text { gazebo } \\
\text { Kebersihan } \\
\text { dan } \\
\text { kenyamanan } \\
\text { kantin }\end{array}$ \\
& $\begin{array}{l}\text { Ketersediaan } \\
\text { sarana dan } \\
\text { forum } \\
\text { komunikasi }\end{array}$ & $\begin{array}{l}\text { Sarana } \\
\text { ibadah yang } \\
\text { memadai }\end{array}$ \\
\hline
\end{tabular}

\section{Tahapan Analisis Data}

Dalam penelitian ini menggunakan Analisis Regresi Logistik, yang akan di analisis adalah data primer yang di dapatkan melalui kuisioner. Adapun tahapan analisisnya adalah sebagai berikut

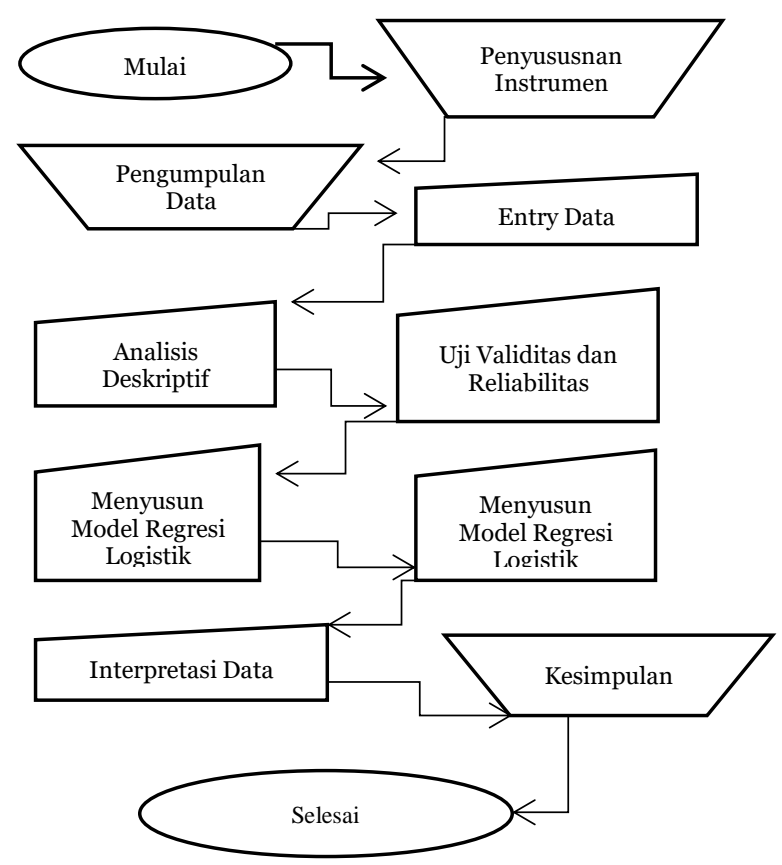

Gambar 1. Alur penelitian

Metode yang digunakan digunakan untuk analisis pengaruh pelayanan difakultas matematika dan ilmu pengetahuan alam terhadap kepuasan mahasiswa fmipa unsrat adalah sebagai berikut :

1. Penyusunan instrument

Penyusunan instrumen kuesioner dilakukan dengan melihat aspek-aspek yang didapat pada Fakultas MIPA. Pertanyaan yang berupa aspekaspek penelitian menggunakan empat skala dengan rincian sebagai berikut:

\begin{tabular}{cc}
\multicolumn{2}{c}{ Tabel 2. Skala Penilaian } \\
\hline Skala & Keterangan \\
\hline 4 & Sangat puas \\
3 & Puas \\
2 & Cukup \\
1 & Tidak Puas \\
\hline
\end{tabular}


2. Pengumpulan Data dan entry data

Pengambilan data dari kuisioner yang dilakukan di fakultas matematika dan ilmu pengetahuan alam universitas sam ratulangi.

3. Analisis Deskriptif

Untuk melihat gambaran data secara umum pada tiap-tiap kuisioner yang telah dipilih oleh responden, analisis deskriptif disajikan dalam bentuk tabel.

4. Uji Validitas dan Reliabilitas

Uji Validitas dan Realibilitas digunakan untuk melihat kevaliditan suatu instrument. Suatu instrumen dianggap valid, apabila mampu mengukur apa yang di inginkan

5. Menyusun Model Regresi Logistik

Pembuatan model dilakukan menggunakan persamaan 7,8,dan 9 .

6. Pengujian Model

Pengujian Model dengan menggunakan Uji statistik G, Uji Wald, Uji kelayakan model.

7. Interpretasi Data

Model regresi logistik ordinal telah di uji dan hasil modelnya baik, signifikannya nyata maka data tersebut dapat diinterpretasikan dengan menggunakan Odd Ratio.

\section{HASIL DAN PEMBAHASAN}

\section{Data Penelitian}

Data dalam penelitian ini adalah mahasiswa aktif tahun ajaran 2018/2019 semester genap Fakultas MIPA sebanyak 1.328 mahasiswa, Sampel terpilih dalam penelitian ini berjumlah 307 diperoleh dengan menggunakan rumus slovin.Namun yg diambil hanya 303 responden.Teknik sampling yg digunakan adalah teknik sampling stratifikasi.Dengan stratifikasi terhadap jumlah mahasiswa program studi.Dengan menggunakan rumus proporsi terhadap jumlah mahasiswa program studi. Dari data yang telah diperoleh bisa dilihat pada tabel berikut :

Tabel 3.Jumlah Responden Per-jurusan

\begin{tabular}{lc}
\hline \multicolumn{1}{c}{ Jurusan } & Responden \\
\hline Matematika & 54 \\
Farmasi & 102 \\
Sistem Informasi & 33 \\
Biologi & 54 \\
Kimia & 39 \\
Fisika & 18 \\
\hline
\end{tabular}

Berdasarkan data yang sudah terkumpul sebanayak 303 responden di Fakultas Mipa didapatkan deskripsi responden. Berdasarkan jurusan responden di Fakultas Mipa diketahui sebanyak 54 responden dari jurusan Matematika, 102 responden dari jurusan Farmasi, 33 responden dari jurusan Sistem Informasi, 54 responden dari jurusan Biologi, 39 responden dari jurusan Kimia, 18 responden dari jurusan Fisika.

Tabel 4.Jumlah Responden Per-semester

\begin{tabular}{lc}
\hline \multicolumn{1}{c}{ Semester } & Responden \\
\hline Semester 2 & 85 \\
Semester 4 & 82 \\
Semester 6 & 69 \\
Semester 8 & 67 \\
\hline
\end{tabular}

Berdasarkan semester responden diketahui sebanyak 85 responden semester 2, 82 responden semester 4, 69 responden semester 6, 67 responden semester 8 .

\section{Uji Validitas dan Reliabilitas Kuisioner}

Uji validitas dan reliabilitas dilakukan pada itemitem pertanyaan untuk melihat korelasi antar pertanyaan dari kuisioner dan melihat kekonsistenan kuisioner. Uji validitas dan reliabilitas dilakukan dengan melakukan survei kepada 30 Mahasiswa Fakultas Matematika dan Ilmu Pengetahuan Alam UNSRAT.

\section{Uji Validitas}

Uji validitas diolah menggunakan SPSS 21. Total responden yang akan diuji adalah 30 responden Mahasiswa Fakultas Matematika dan Ilmu Pengetahuan Alam UNSRAT. Hipotesis yang akan diuji adalah :

$H_{0}$ : Tidak adanya korelasi antar pertanyaan kuisioner $\left(r_{\text {hitung }}<r_{\text {tabel }}\right)$

$H_{1}$ : adanyakorelasi antar pertanyaan kuisioner $\left(r_{\text {hitung }}>\right.$ $\left.r_{\text {tabel }}\right)$

Taraf kepercayaan yang digunakan adalah $95 \%$ $(\alpha=0,05)$.Pengujian validitas dilakukan dengan cara membandingkan nilai $r$ hitung dengan $r$ tabel. Apabila hasil pengujian menunjukkan $r$ hitung lebih besar dari $r$ tabel, berarti ada korelasi $H_{0}$ ditolak) atau pertanyaan memiliki validitas. Berdasarkan hasil pengujian menggunakan SPPS 21 maka didapat hasil uji validitas seperti yang terlihat pada tabel 5 .

Hasil pengujian Uji Validitas untuk setiap butir pertanyaan pada 3 aspek yang di nilai yaitu aspek administrasi, aspek pengajaran, dan aspek sarana prasarana di Fakultas Mipa diketahui bahwa nilai korelasi semua butir pertanyaan lebih besar dari $r$ tabel dengan $(0,361)$ sehingga keputusannya adalah tolak H_o dan terima H_1. Kesimpulannya dari uji validitas 
adalah bahwa ada keterkaitan pada setiap butir pertanyaan di kuisioner.

Tabel 5. Hasil Validitas Kuisioner

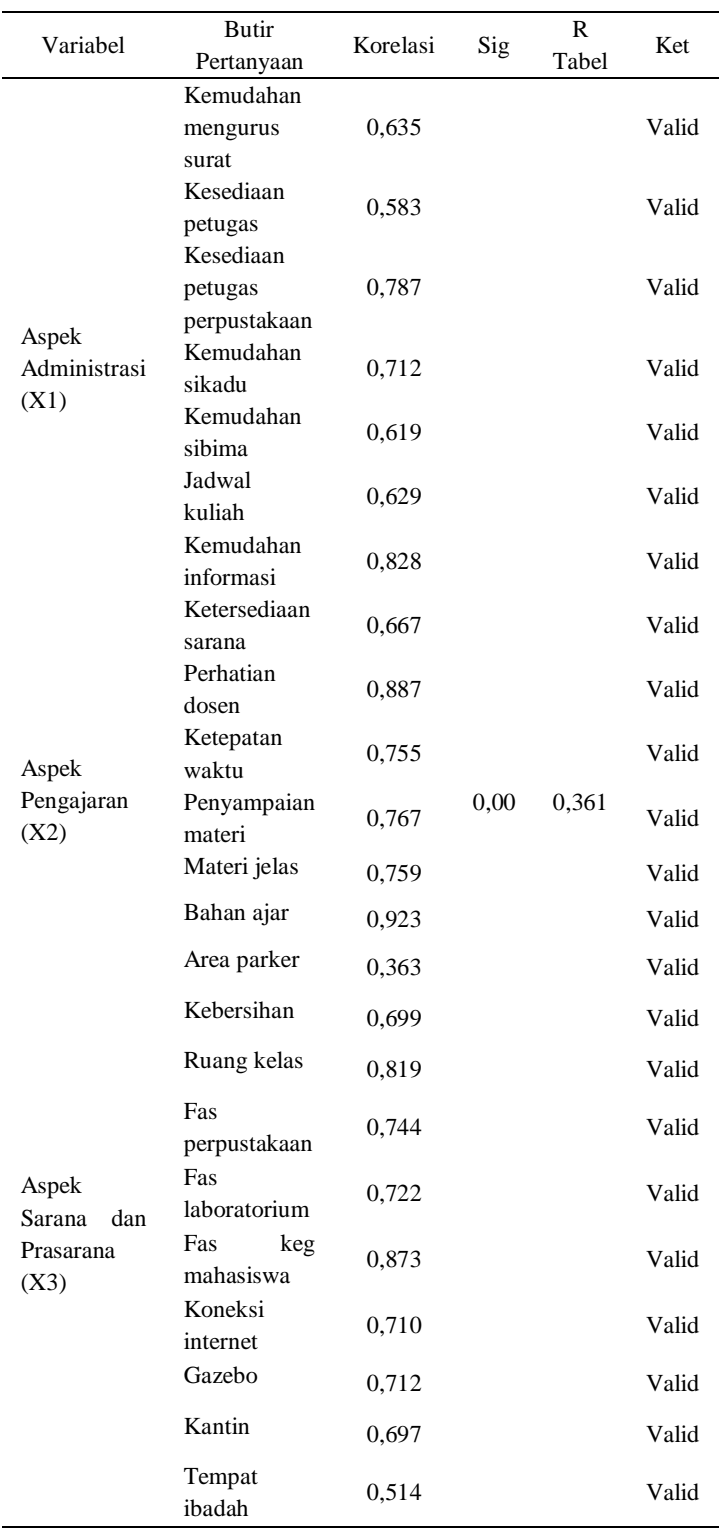

Tabel 6. Model Regresi Logistik Ordinal

\begin{tabular}{|c|c|c|c|c|c|c|}
\hline $\begin{array}{l}\text { Estimat } \\
\mathrm{e}\end{array}$ & $\begin{array}{l}\text { Std. } \\
\text { Error }\end{array}$ & Wald & $\begin{array}{l}D \\
f\end{array}$ & Sig. & $\begin{array}{l}95 \% \text { CoI } \\
\text { Interva } \\
\text { Lowe } \\
\mathrm{r} \\
\text { Boun } \\
\mathrm{d}\end{array}$ & $\begin{array}{l}\text { fidance } \\
\text { Upper } \\
\text { Bound }\end{array}$ \\
\hline 6.175 & .780 & 62.754 & 1 & .000 & 4.647 & 7.703 \\
\hline 10.121 & .933 & 117.768 & 1 & .000 & $\begin{array}{l}8.29 \\
3\end{array}$ & 11.949 \\
\hline 13.687 & 1.098 & 155.411 & 1 & .000 & $\begin{array}{l}11.53 \\
5\end{array}$ & 15.838 \\
\hline .248 & .052 & 22.693 & 1 & .000 & .146 & .351 \\
\hline .274 & .060 & 20.746 & 1 & .000 & .156 & .392 \\
\hline .045 & .022 & 3.989 & 1 & .046 & .001 & .089 \\
\hline
\end{tabular}

\section{Model Regresi}

Berikut adalah hasil pendugaan model regresi logistik ordinal pada pelayanan Fakultas MIPA terhadap kepuasan mahasiswa menggunakan software SPSS 21.

Dari Output yang terlihat pada tabel 6 di hasilkan persamaan regresi logistic sebagai berikut :

$$
\begin{array}{r}
\text { Logit }\left(Y_{0}\right)=6,175+0,248 x_{1}+0,274 x_{2}+0,045 x_{3}(7) \\
\operatorname{Logit}\left(Y_{1}\right)=10,121+0,248 x_{1}+0,274 x_{2}+0,045 x_{3}(8) \\
\operatorname{Logit}\left(Y_{2}\right)=13,687+0,248 x_{1}+0,274 x_{2}+0,045 x_{3}(9) \\
\text { Hasil tersebut berdasar dari melihat rumus, }
\end{array}
$$
dimana nilai $\theta^{\wedge}$ merupakan nilai variabel konstanta, jika dilihat dari output diatas variabel konstanta bisa dilihat pada kolom Estimate dan pada baris Threshold dengan nilai parameter dalam aspek administrasi sebesar 6,175, aspek pengajaran sebesar 10,121 dan aspek sarana dan prasarana sebesar 13,687. Sedangkan nilai $\beta^{\wedge}$ merupakan nilai variabel prediktor, jika dilihat dari output diatas variabel prediktor bisa dilihat pada kolom Estimate dan pada baris Location dengan nilai parameter dalam aspek administrasi sebesar 0,248, aspek pengjaran sebesar 0,274, dan aspek sarana dan prasarana sebesar 0,045. Maka dapat dihasilkan persamaan seperti pada persamaan $(7,8$, dan 9$)$.

\section{Pengujian Parameter Model Regresi Uji Wald}

Tabel 7.Pengujian Parameter Model Regresi dengan Uji Wald

\begin{tabular}{lllllll}
\hline $\begin{array}{l}\text { Estim } \\
\text { ate }\end{array}$ & $\begin{array}{l}\text { Std. } \\
\text { Erro }\end{array}$ & Wald & $\begin{array}{l}\text { D } \\
\mathrm{f}\end{array}$ & & Sig. & \multicolumn{3}{l}{$\begin{array}{l}\text { 95\%Confidance } \\
\text { Interval } \\
\text { Lower } \\
\text { Bound }\end{array}$} & $\begin{array}{l}\text { Upper } \\
\text { Bound }\end{array}$ \\
\hline 6.175 & .780 & 62.754 & 1 & .000 & 4.647 & 7.703 \\
10.121 & .933 & 117.768 & 1 & .000 & 8.293 & 11.949 \\
13.68 & 1.09 & 155.411 & 1 & .000 & 11.535 & 15.838 \\
7 & 8 & & & & & \\
.248 & .052 & 22.693 & 1 & .000 & .146 & .351 \\
.274 & $\begin{array}{l}.06 \\
0\end{array}$ & 20.746 & 1 & .000 & .156 & .392 \\
.045 & .022 & 3.989 & 1 & .046 & .001 & .089 \\
\hline
\end{tabular}

Hasil pengujian parameter pada tabel di atas menjelaskan bahwa variabel administrasi, variabel pengajaran dan variabel sarana prasarana adalah variabel yang mempunyai pengaruh signifikan terhadap kepuasan secara umum di Fakultas MIPA UNSRAT dikarenakan variabel tersebut mempunyai nilai signifikan $<\alpha(0,05)$ atau dengan kata lain tolak $\boldsymbol{H}_{\mathbf{0}} \mathbf{j i k a}$ $Z^{2}>X_{(\alpha, 1)}^{2}(3,84)$

Berdasarkan analisis uji kelayakan model persamaan logistik ordinal bisa dipakai untuk menganalisis tingkat kepuasan mahasiswa (Y).Hal ini diketahui karena nilai sig>0,05.Dari hasil analisis regresi logistik diatas dihasilkan 3 persamaan regresinya, interpretasi dari ketiga persamaan tersebut bisa dilihat dalam bab pembahasan interpretasi model. 


\section{Pengaruh Pelayanan Di Fakultas Matematika dan Ilmu Pengetahuan Alam Terhadap Kepuasan Mahasiswa FMIPA UNSRAT Menggunakan Analisis Regresi Logistik Ordinal \\ d'Cartesian : Jurnal Matematika dan Aplikasi, Vol. 8 No. 2 (September 2019): 153-160}

\section{Koefisien Determinasi Model}

Besarnya nilai koefisien determinasi pada model regresi logistik ditunjukan oleh nilai Mc Fadden, Cox dan Snell, Nagelkerke R Square. Tabel Determinasi dapat dilihat pada Tabel 8.

Tabel. 8. Koefesien Determinasi

\section{Pseudo R-Square}

\begin{tabular}{ll}
\hline Cox and Snell & .449 \\
Nagelkerke & .503 \\
McFadden & .267 \\
\hline
\end{tabular}

Link function: Logit.

abel diatas menunjukan nilai koefisien determinasi $\mathrm{Mc}$ Fadden sebesar 0,267 sedangkan koefisien dterminasi Cox dan Snell sebesar 0,449 dan koefisien determinasi Nagelkerke sebesar 0,503 atau sebesar 50,3\%. Koefisien Nagelkerke sebesar 50,3\% berarti variabel independen aspek administrasi, aspek pengajaran, dan aspek sarana prasarana mempengaruhi penilaian kepuasan secara umum sebesar 50,3\% sedangkan 49,7\% dipengaruhi oleh faktor lain yang tidak termasuk dalam pengujian model.

\section{Interpretasi Model}

Jika model regresi logistic ordinal telah diuji dan hasil modelnya baik dan signifikannsinya nyata maka data tersebut dapat di interpretasikan dengan menggunakan uji odd ratio.

Odd ratio aspek administrasi $\left(x_{1}\right): \psi=e^{0.248}=$ 1.28. Hal ini dapat diartikan bahwa peluang seorang mahasiswa merasa sangat puas pada pelayanan aspek administrasi 1.28 kali dibandingkan dengan mhasiswa yang tidak merasa puas.

Odd ratio aspek pengajaran $\left(x_{2}\right): \psi=e^{0.274}=$ 1.31. Hal ini dapat diartikan bahwa peluang seorang mahasiswa merasa sangat puas pada pelayanan aspek pengajaran 1.31 kali dibandingkan dengan mhasiswa yang tidak merasa puas.

Odd ratio aspek sarana prasarana $\left(x_{3}\right): \psi=$ $e^{0.45}=1.56$ Hal ini dapat diartikan bahwa peluang seorang mahasiswa merasa sangat puas pada pelayanan aspek sarana prasarana 1.28 kali dibandingkan dengan mhasiswa yang tidak merasa puas.

\section{KESIMPULAN DAN SARAN \\ Kesimpulan}

1. Model persamaan logistik Ordinal terhadap pengaruh pelayanan di Fakultas Matematika Dan Ilmu Pengetahuan Alam terhadap kepuasan Mahasiswa FMIPA UNSRAT:

Logit $\left(\mathrm{Y} \_0\right)=6,175+0,248 x_{1}+0,274 x_{2}+0,045 x_{3}$

Logit $\left(\mathrm{Y} \_1\right)=10,121+0,248 x_{1}+0,274 x_{2}+0,045 x_{3}$

Logit $\left(Y \_2\right)=13,687+0,248 x_{1}+0,274 x_{2}+0,045 x_{3}$

2. Berdasarkan Hasil uji Wald diketahui semua variabel yang berpengaruh secara signifikan terhadap kepuasan secara umum di Fakultas MPA UNSRAT adalah $\boldsymbol{X}_{\mathbf{1}}=$ Aspek Administrasi dan
$\boldsymbol{X}_{\mathbf{2}}=$ Aspek Pengajaran dan $\boldsymbol{X}_{\mathbf{3}}=$ Aspek Sarana dan Prasarana.

3. Berdasarkan koefisien determinasi Nagelkerke sebesar 0,503 atau sebesar 50,3\%. Hal ini berarti bahwa variabel independen aspek administrasi, aspek pengajaran, dan aspek sarana dan prasarana mempengaruhi penilaian kepuasan pelayanan di Fakultas MIPA UNSRAT secara umum sebesar $50,3 \%$.

\section{Saran}

Sangat di harapkan untuk pelayanan di fakultas Matematika dan Ilmu Pengetahuan Alam agar supaya tetap konsisten dalam melayani keperluan mahasiswa dalam urusan administrasi, pengajaran, sarana dan prasarana dan juga mengutamakan kepuasan dari mahasiswa.

\section{REFERENSI}

[1] Semiawan Conny R. (1998). Perkembangan dan belajar peserta didik. Jakarta:Depdikbud Dirjen Pendidikan Tinggi Proyek Pendidikan Guru Sekolah Dasar.

[2] Tjiptono, F. 2004. Manajemen Jasa, Edisi Pertama. Yogyakarta: CV Andi Offse [1-10] Agresti,A. 1990. Categorical Data Analysis. New York: JohnWiley\& Sons.Inc.

[3] Hatidja D.,dan L. I. Momuat.,dan C.Mongi. 2018. Pengelompokan Mata Kuliah Di Program Studi Fisika FMIPA UNSRAT Berdasarkan Proses Pembelajaran Menggunakan Analisis Cluster. Universitas Sam Ratulangi. Manado. Jurnal Ilmiah Sains 18(2) : 108

[4] Supranto. J, 2006, Pengukuran Tingkat Kepuasan Pelanggan : Untuk Menaikkan Pangsa Pasar, Jakarta, Rineka Cipta

[5] Ratminto dan Atik,. 2005. Manajemen Pelayanan, disertai dengan pengembangan model konseptual, penerapan citizen's charter dan standar pelayanan minimal. Yogyakarta: Pustaka Pelajar

[6] Nirwana. S.R.A. 2015.Regresi Logistik Multinomial dan Penerapannya dalam Menentukan Faktor yang Berpengaruh pada Pemilihan Program Studi di Jurusan Matematika UNM.Skripsi.Universitas Negeri Makassar.Makassar.

[7] Sepang, F. 2012. Penerapan Regresi Logistik untuk Menentukan Faktor-faktor yang Mempengaruhi Pemilihan Jenis Alat Konstrasepsi di Kecamatan Modayag Barat.Universitas Sam ratulangi. Manado. Jurnal MIPA 1(1) : 1-5

[8] Hosmer, D.W., dan S. Lemeshow. 2000. Applied Logistic Regression. John Wiley dan Son. New York.

[9] Ratnasari, V. 2013. Analisis Regresi Logistik Ordinal Terhadap Faktor-faktor yang Mempengaruhi Predikat Kelulusan Mahasiswa S1 di ITS Surabaya. Institut Teknologi Sepuluh Nopember. Surabaya. 
[10] Agresti,A. 1990. Categorical Data Analysis. New York : JohnWiley\& Sons.Inc.

[11] Kleinbaum D. dan Klein, M. 2002.Logistic Regression.New York:SpringerVerlag.

FadhilaMinabari (Fadhila_minabari@yahoo.com)

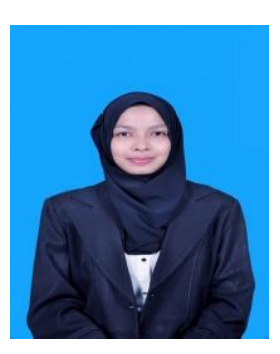
lahir dan tinggal di Manado, Sulawesi utara.Menempuh pendidikan tinggi Program Studi Matematika dan Ilmu Pengetahuan Alam Universitas Sam Ratulangi Manado. Tahun 2019 adalah tahun terakhir ia menempuh studi. Makalah ini merupakan hasil penelitian skripsinya yang di publikasikan.

Jullia Titaley (july titaley@unsrat.ac.id)

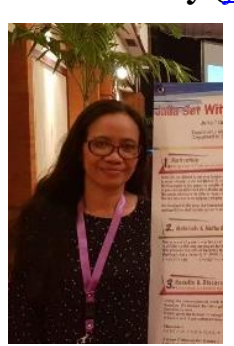

Pada tahun 1997, memperoleh gelar sarjana di Program Studi Matematika, Universitas Pattimura Ambon. Gelar Magister Sains diperoleh dari Universitas Gajah Mada pada tahun 2001. Menjadi dosen di Jurusan Matematika, FMIPA, Universitas Sam Ratulangi Manado sejak tahun 2002 sampai sekarang dengan bidang keahlian yang ditekuni diantaranya; Analisis, Aljabar, dan Geometri.

Nelson Nainggolan (n-nelson@unsrat.ac.id)

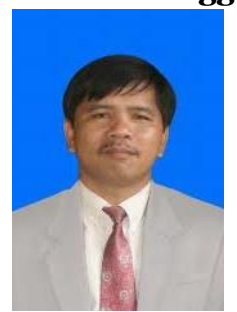

Lahir di Tapanuli Utara tanggal 9 Maret 1967. Gelar sarjana pendidikan Matematika diperoleh tahun 1992 di FMIPA IKIP Negeri Medan. Tahun 1996 menyelesaikan studi S2, di jurusan Matematika ITB Bandung. Tahun 2011 menyelesaikan studi S3 pada bidang Matematika di Universitas Padjadjaran Bandung. Saat ini menjadi pengajar akademik tetap di jurusan Matematika FMIPA Unsrat Manado. 